\title{
Judo through the prism of the Russian dissertations
}

\author{
Darya Mikhaylova ${ }^{1 *}$ \\ ${ }^{1}$ Law and Civil Security's Department of Management and Social Technologies' Institute, Theory and \\ Methods of Physical Culture's Department of Martial Arts and Non-Olympic Sports' Faculty, The \\ Federal State Budget Educational Institution of the Higher Education "National State University of \\ Physical Culture, Sport and Health named after P. F. Lesgaft, Saint-Petersburg", Saint-Petersburg, \\ Russia
}

\begin{abstract}
The research touches on an interesting and important, both theoretically and practically, scientific problem that lies in the contradiction between two circumstances. The first circumstance is the large number of the Russian dissertations on judo. And the second circumstance is the lack of that scientific information, the knowledge of which would determine a significant increase in the sports' achievements of Russian judokas. In the whole the elimination of this contradiction is necessary for the integrated management of increasing the competitiveness of the sports' achievements of Russian judokas. In addition, the solution to this contradiction is also relevant in the context of the fact that full knowledge about the judo's phenomenon, about judo as a weapon and about the ways of judo's mastering is available mainly to the Japanese as the judo's founders. The purpose of this research is to clarify the promising directions of the Russian dissertations on judo as a theoretical and methodological basis for increasing the effectiveness of Russian judo on the world sports' arena. The methods of this research: comparative method, case studies, content's analysis, frequence's analysis, conjugation's tables' analysis, genetic method, theoretical modeling. The results of a systematic analysis of all Russian dissertations on judo (for the entire period over forty years) are presented, the composition of these dissertations and significant relationships between their main characteristics are uncovered, gaps in scientific knowledge in judo are identified, and the necessary directions for further dissertational researches in this area are outlined.
\end{abstract}

\section{Introduction}

\section{Definition of the concept}

From a traditional point of view (as shown in Figure 1), the judo's phenomenon is defined as a "soft path" and an Olympic sport characterized as a type of wrestling that most stimulates the effective manifestation of intellectual abilities, that is, tactically flexible / non-standard, creative / non-repetitive / selective, that is, adequate to the situation. In the mirror of communication theory, the concept of "verbal judo" [1] is considered as a soft

* Corresponding author: $\underline{\text { d-samuray@ yandex.ru }}$ 
way of persuasion and the technology of successful communication, a system of communication's self-defense. In the mirror of economics, the concept of "judo's strategy" [2] is interpreted as a style of thinking, a characteristic's feature of which is the absence of the desire to resist force by force.

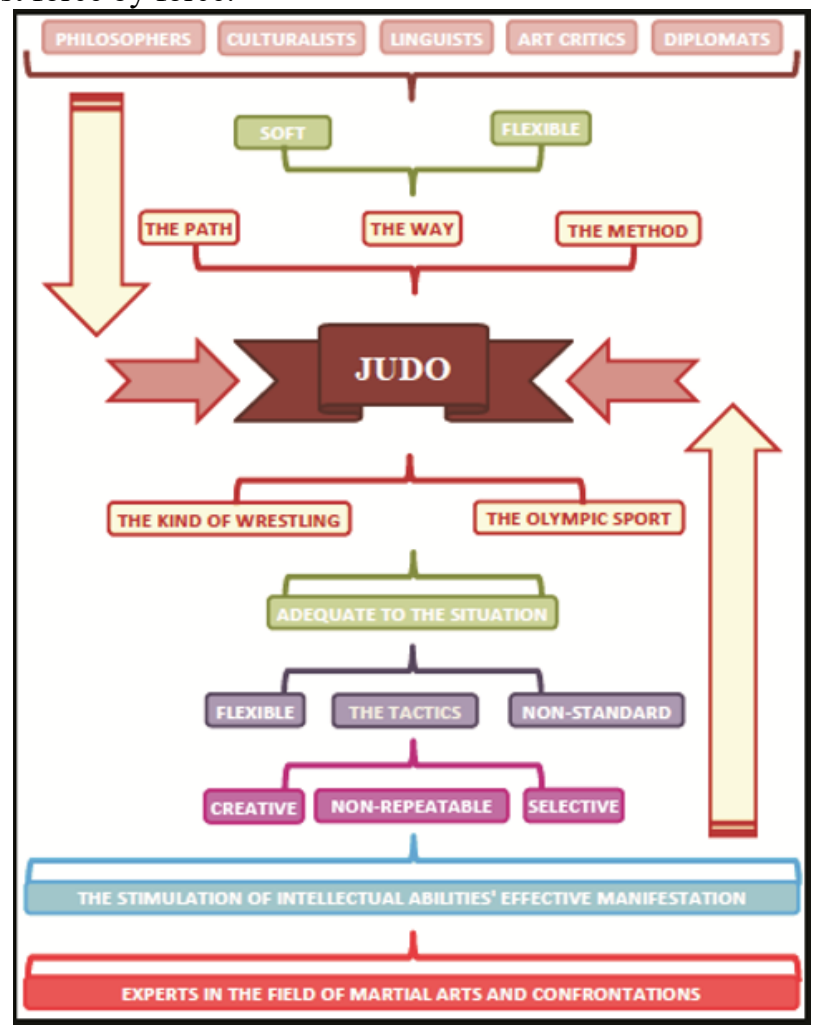

Fig. 1. The traditional view in understanding of the judo's phenomenon.

Within the framework of the Russian dissertations in the field of judo, there are still no works that analyze the innovative problems of judo related to the complex presentation of this concept, as well as its particular alternative interpretations.

Determination of the relevance of the research

Taking into account the fact that the Japanese are the undisputed leaders in judo on the world's sports' arena, it is obvious that their training system is of significant interest. It should be noted that judo is considered by the Japanese in the best samurai's traditions as a type of weapon and as a symbol demonstrating their ability to defend themselves from a potential enemy [3-4]. This fact explains why the Japanese consider the methods of training in judo as a secret information and do not share them in full. In this regard, the necessity for independent researches in the field of judo is actualized in order to reveal the entire spectrum of scientific knowledge about it.

\section{Literature review}

The Russian dissertations in the field of judo for the degree of Doctor of Science

To date, the leading researches in the Russian scientific field in judo include the dissertations for the degree of Doctor of Science. So, the first doctoral dissertation in the 
field of judo was defended in 1990 by Ya. K. Koblev [5], who considered the system of long-term training of the international class athletes in judo's wrestling. The next scientist was O. A. Sirotin [6], who analyzed the psychological and pedagogical foundations of individualization of judokas' sports' training (1996). He was followed by A. V. Eganov [7], who was the first to reveal the management's essence of the training process and judokas' sports' skills increasing (1999). Then V. G. Pashintsev conducted a research [8], in which in 2001 it was proposed the technology of designing long-term training of judokas (the second doctoral dissertation in long-term training in judo). In the same year, V. V. Izvekov [9] returned to the topic of management in judo, his dissertation dealt with the management's system of female training in wrestling on the example of judo. In 2003, A. G. Levitsky [10] successfully defended his next dissertation on management in judo: this time the issue of management of judokas' training was considered, taking into account the level of individual readiness for competitive activity. Further, twelve years later, in 2015, two doctoral dissertations were defended: by V. G. Pashintsev [11] (already known to us, he eventually defended two doctoral dissertations, both in the scientific field of judo - one - on pedagogical, and the other - on biological sciences) - on the adaptation of bioenergetic processes in the development of endurance and speed-strength's qualities of the qualified judokas and by S. B. Elipkhanov [12] - on the management of long-term strength's training in female judo (the next doctoral dissertation on the management in judo is the fourth and the last, in particular - the second doctoral dissertation on the management in female judo).

The Scientific articles in the field of judo in Russian peer-reviewed journals

An analysis of scientific articles in the field of judo in Russian peer-reviewed journals shows that the most researched topics include the competitive ability, the reliability, the preparation, the preparedness and the success [13-18] and the biomechanical aspects of judo [19-24] - high level of knowledge (submitted by six articles each), the judokas' anthropometric and morphological features [25-27] and the questions of strategy and tactics in judo [28-30] - middle level of knowledge (submitted by three articles for each), the problems of female judo, the physiological characteristics of judokas, the ways of endurance's developing, the aspects of the psychological preparation and the options for national types of wrestling's using in judokas' training [31-40] - low level of knowledge (submitted by two articles for each), so, in other words, one can expect the defenses of the dissertations on these topics in the near future. Other topics have been minimally researched so far [41-51].

\section{The methodology of the research}

The organization of the research. The analysis of all dissertations in the field of judo ( $n=134$; according to the funds of Russian State Library), conducted both in the USSR and in the Russian Federation, the synthesis of information received and its structuring using content's analysis made it possible to characterize the composition and content of these researches and also classify them according to several criteria.

The methods of the research (according to the classification of B. G. Ananyev in the modification of E. R. Yakhontov [52] for sports' and pedagogical researches and with the author's supplement): comparative method, case studies, content's analysis, frequence's analysis, conjugation's tables' analysis, genetic method, theoretical modeling. 


\section{Results of the research}

\subsection{Results from descriptive statistics (frequence's analysis)}

The criterion "the scale of the research"

As shown in Figure 2, it was revealed that only $6 \%$ of all dissertations related to judo are the researches for the Doctor of Science's degree (first-order scale - general) and the rest of them (94\%) are the researches for the degree of candidate of sciences (second-order scale - private).

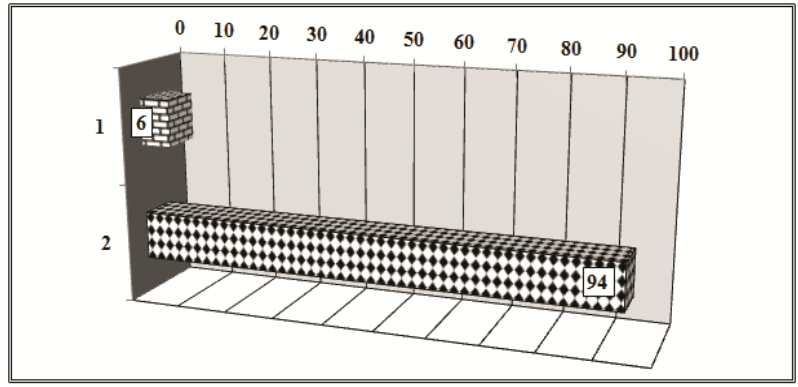

Fig. 2. The proportion of the dissertations in the field of judo by the criterion "the scale of the research" $(n=134)$ (Note: the doctoral dissertations; 2 - the PhD theses).

\section{The criterion "the researcher's gender"}

Figure 3 shows the distribution of the dissertations in the field of judo depending on the researcher' gender. It was revealed that most of the dissertations were carried out by male researchers (about 93\%), so, it was revealed that gender's inequality in research's activities in the field of judo is present among Russian scientists.

The criterion "the year of research's holding"

As shown in Figure 4, it is obvious that researches in the field of judo have been conducted from 1980 to the present, and the peaks of the dissertations' defenses are characterized by 2007 (about 6\% of all analyzed researches), 2013 (about 5\% of all analyzed researches), 2005 and 2006 (just over 4\% of all analyzed researches for each year). It can also be noted that in 1981, 1983, 1991, 1994, 2016 and 2018, the minimum popularity of the scientific topic was observed, but, at the same time, not a single year has been revealed in forty years when the dissertations' defenses on the scientific topic were not carried out.

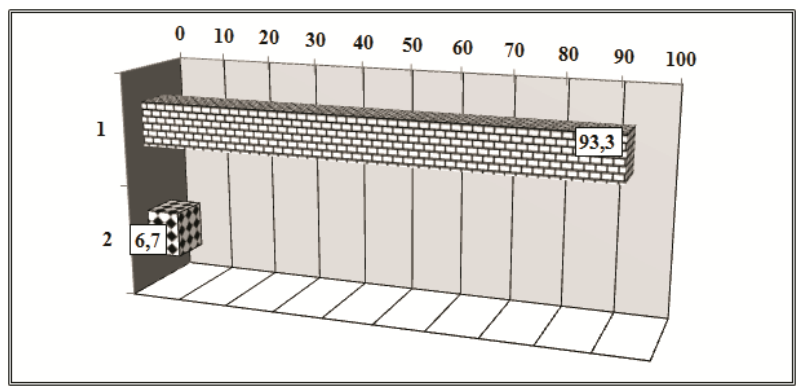

Fig. 3. The proportion of the dissertations in the field of judo by the criterion "the researcher's gender" $(n=134)$ (Note: the male researchers; 2 - the female researchers). 


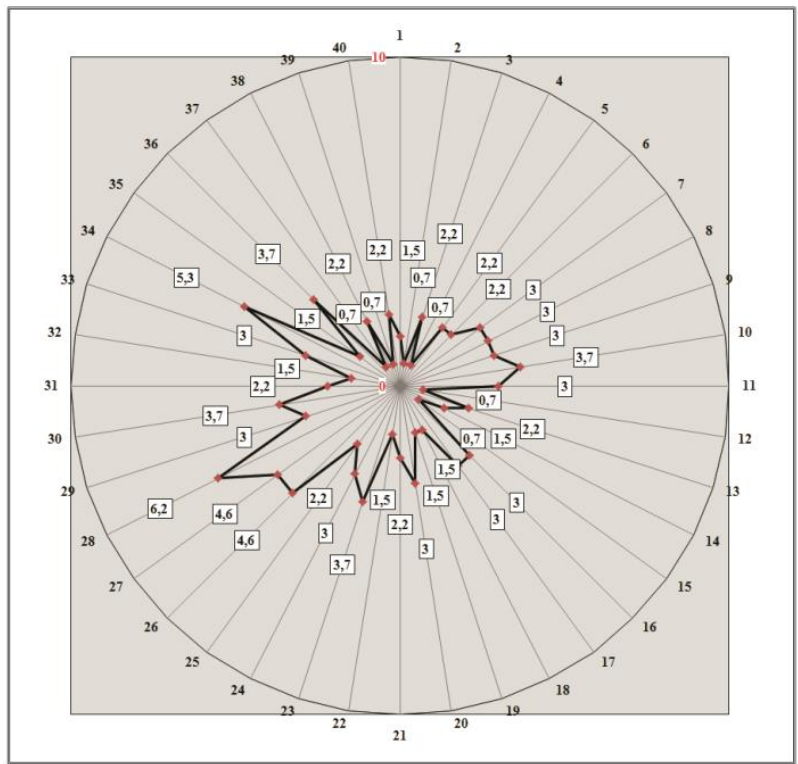

Fig. 4. The proportion of the dissertations in the field of judo by the criterion "the year of research's holding" ( $\mathrm{n}=134)$ (Note: $1-1980 ; 2-1981 ; 3-1982 ; 4-1983 ; 5-1984 ; 6-1985 ; 7-1986 ; 8-$ $1987 ; 9-1988 ; 10-1989 ; 11-1990 ; 12-1991 ; 13-1992 ; 14-1993 ; 15-1994 ; 16-1995 ; 17-$ $1996 ; 18-1997 ; 19-1998 ; 20-1999 ; 21-2000 ; 22-2001 ; 23-2002 ; 24-2003 ; 25-2004 ; 26-$ $2005 ; 27-2006 ; 28-2007 ; 29-2008 ; 30-2009 ; 31-2010 ; 32-2011 ; 33-2012 ; 34-2013 ; 35-$ $2014 ; 36-2015 ; 37-2016 ; 38-2017 ; 39-2018 ; 40-2019)$.

\section{The criterion "the decade of research's holding"}

Thus, we systematize the data by decades. As can be seen from Figure 5, the peak of the dissertations' defenses in the field of judo falls on the 2000s (about 35\%), the decline in defenses falls on the nineties, which is quite explainable by the difficult socio-economic conditions in modern Russia of those years (about 20\%), at that time as the activity of the defended dissertations in the eighties and in the period from 2010 to the present is approximately the same.

The criterion "the scientific specialty"

Figure 6 shows the distribution of the dissertations in the field of judo, depending on the scientific specialties in which they were conducted. Thus, it can be concluded that about $93 \%$ of all dissertations in the field of judo were defended within the framework of the scientific specialty 13.00.04 - Theory and methodology of physical education, sports' training, health-improving and adaptive physical culture, while about $3 \%$ of works were defended in the scientific specialty 03.00 .13 - Physiology. In addition, it turned out that only just over $1 \%$ of the dissertations in the field of judo was completed in two scientific specialties. 


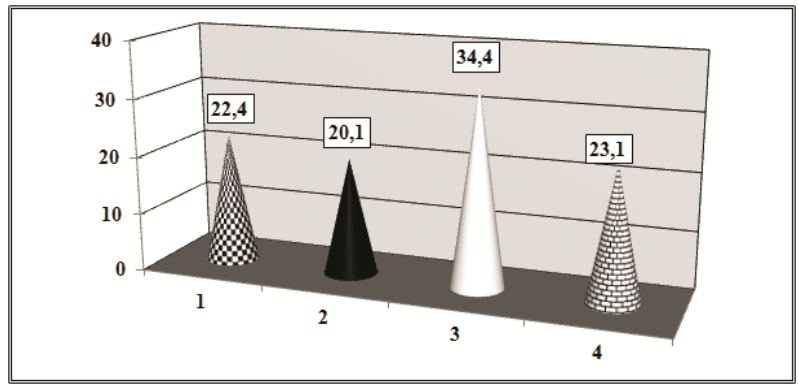

Fig. 5. The proportion of the dissertations in the field of judo by the criterion "the decade of research's holding" ( $n=134$ ) (Note: 1 - the eighties; 2 - the nineties; 3 - the 2000s; 4 - the period from 2010 to the present).

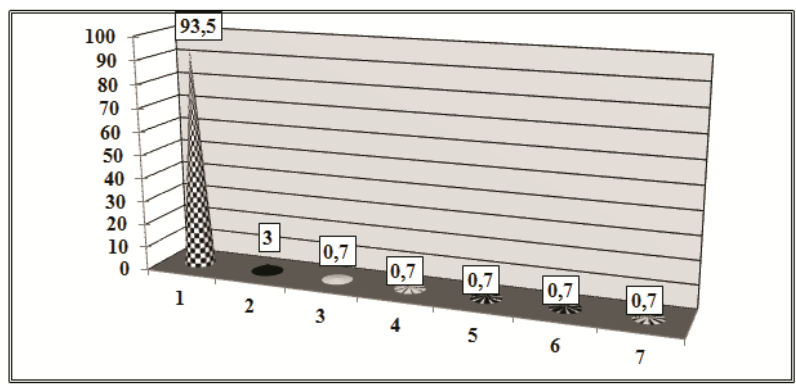

Fig. 6. The proportion of the dissertations in the field of judo by the criterion "the scientific specialty" $(n=134)$ (Note: $1-13.00 .04$ - Theory and methods of physical education, sports' training, healthimproving and adaptive physical culture; $2-03.00 .13$ - Physiology; $3-13.00 .04$ - Theory and methodology of physical education, sports' training, health-improving and adaptive physical culture and 03.00.13 - Physiology; 4 - 13.00.01 - General pedagogy, history of pedagogy and education; 5 03.03.01 - Physiology; 6 - 14.00.16 - Pathological physiology; 7 - 14.00.12 - Physical therapy and sports' medicine and 14.00.01 - Obstetrics and gynecology).

\section{The criterion "the area of sciences"}

Systematizing information by fields of sciences (Fig. 7), we determine that about $93 \%$ of all dissertations in the field of judo were defended in the framework of pedagogical sciences, while only about $4 \%$ of the dissertations were defended in the field of biological sciences, and in total just over $1 \%$ of the dissertations was defended in the field of medical sciences.

\section{The criterion "the contingent"}

Classification of the dissertations in the field of judo by the contingent (Fig. 8), which was considered, made it possible to reveal that about $25 \%$ of all works were performed without differentiating the contingent, that is, they reflect general issues of judo, about $21 \%$ of all works are related to a close analysis of the training technologies in judo for a contingent from ten to twelve years old (including at the stage of initial training), about $20 \%$ of all works reveal the essence and mechanisms of training the highly qualified athletes, the sports' teams and elite judo. 


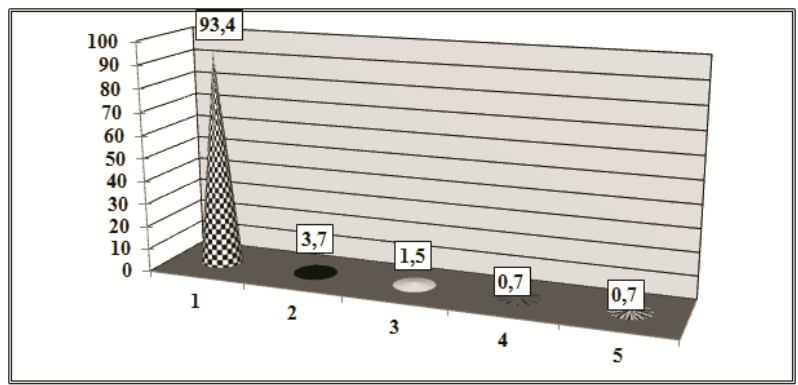

Fig. 7. The proportion of the dissertations in the field of judo by the criterion "the area of sciences" (n = 134) (Note: 1 - pedagogical sciences; 2 - biological sciences; 3 - medical sciences; 4 psychological sciences; 5 - the area "physical education and sports").

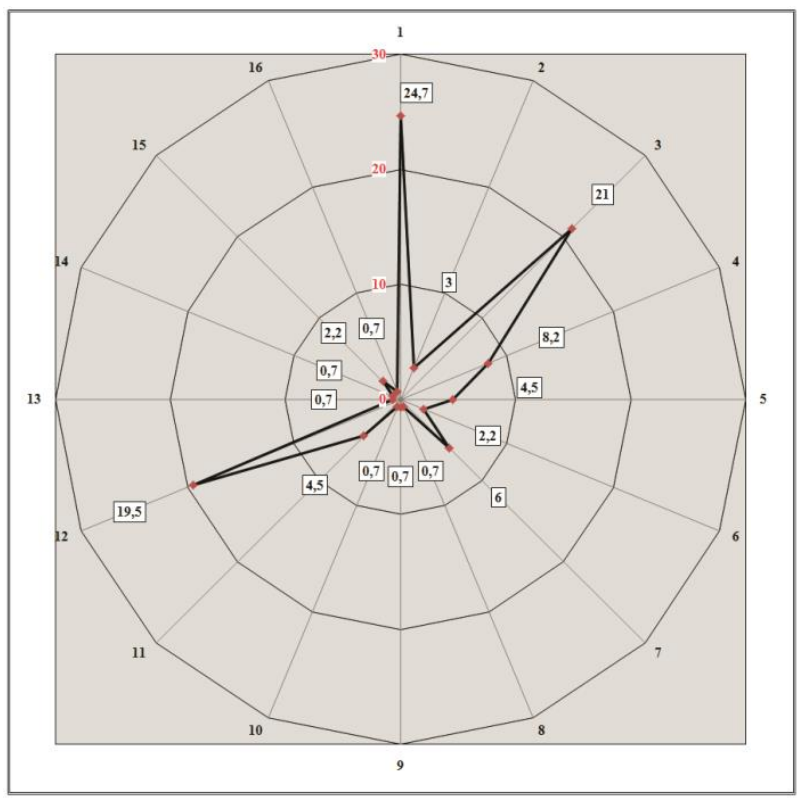

Fig. 8. The proportion of the dissertations in the field of judo by the criterion "the contingent" $(\mathrm{n}=$ 134) (Note: 1 - without differentiation of the contingent; 2 - the kids - up to the stage of initial training - from six to seven years, initial training from seven to ten years; 3 - the children - initial training from ten to twelve years; 4 - the adolescence from twelve to sixteen (female) / seventeen (male) years; 5 - the adolescence from sixteen (female) / seventeen (male) to twenty (female) / twenty one (male) years; 6 - the juniors (from nineteen to twenty two years old); 7 - the students; 8 - those, who involved in educational and training groups; 9 - the practicing groups of sports' improvement; 10 - the practicing educational training groups and the groups of sports' improvement; 11 - the qualified athletes, the athletes of senior sports' categories; 12 - the highly qualified athletes, the athletes of the national teams, the elite athletes; 13 - the military personnel (judo in the Armed Forces); 14 - the trainers-teachers; 15 - the female judokas (female judo); 16 - the judges).

\section{The criterion "the research's topic in the field of judo"}

Classification of the dissertational researches in the field of judo according to the research's topic (Fig. 9) made it possible to determine that the largest number of works $(20 \%)$ is associated with the analysis of the mechanisms of organizing tactical preparation and increasing tactical preparedness, the ways of mastering technical-tactical and tactical- 
technical motor actions, then, about $11 \%$ of works reflect the analysis of the effective mechanisms of judo's teaching, the organization of technical preparation and the improvement of technical preparedness, almost $6 \%$ of works reveal the system of management in judo, as well as, the mechanisms of organizing physical preparation and improving physical preparedness. The remaining sections of the analysis (twenty three out of twenty seven sections) are presented on a smaller scale, however, the very fact that such a large number of sections, which have been identified, allows us to conclude that, in general, the range of topics in the field of judo has been quite well mastered by researchers, although not exhausted.

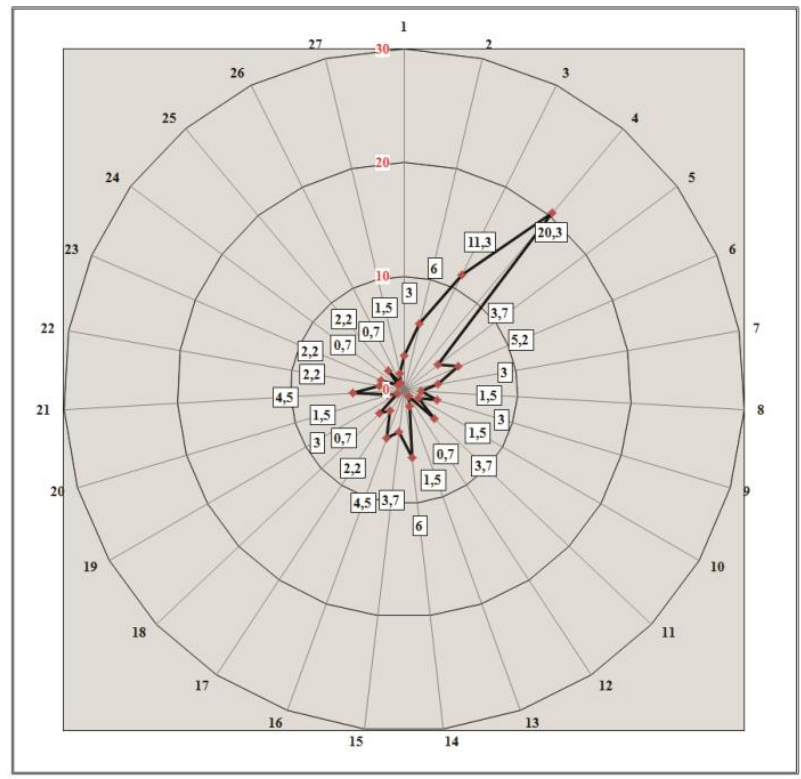

Fig. 9. The proportion of the dissertations in the field of judo by the criterion "the research's topic in the field of judo" $(n=134)$ (Note: 1 - the long-term preparation; 2 - the physical preparation and the physical preparedness; 3 - the technical preparation and the technical preparedness, teaching; 4 - the tactical preparation and the tactical preparedness, mastering technical-tactical and tactical-technical motor actions; 5 - the strength's preparation and the strength's preparedness; 6 - the endurance and the working capacity; 7 - the coordination's abilities; 8 - the complexes for the physical abilities' formation; 9 - the planning; 10 - the programming; 11 - the modeling; 12 -the forecasting; 13 -the organization as a management function; 14 - the management; 15 - the appraisal; 16 - the sports' preparation; 17 - the preparation in the education; 18 - the individualization; 19 - sports' training and the sports' fitness; 20 - the competitive (sports') reliability; 21 - the impact of judo on health and the state of the athlete's body; 22 - the psychological preparation and the psychological preparedness; 23 - the sports' selection and the initial preparation (without the differentiation of the contingent); 24 judo in the Armed Forces; 25 - judo in the physical education; 26 - the judo's refereeing; 27 - the education and the development by means of judo).

\subsection{Results from explanatory statistics (conjugation's tables' analysis)}

The conjugation's tables' analysis between the selected determinants of the considered Russian dissertations in the field of judo makes it possible to rank these determinants according to the criterion of significance (Fig. 10).

So, the first in importance (five interconnections for each) were the research's topic in the field of judo of the author's synopsis or of the dissertation in the field of judo and the code of the scientific specialty, within the framework of which the analyzed Russian 
dissertations in the field of judo were carried out. After them, the second most important determinant (four interconnections) was the scale of the analyzed Russian dissertations in the field of judo. Then, the third in importance (three interconnections for each) were the year of publication of the author's synopsis or the presentation of the dissertation under consideration for the defense, the researcher's gender and the area of sciences, within which the analyzed Russian dissertations in the field of judo were carried out. Further, the fourth place (two interconnections) was taken by the contingent analyzed in the Russian dissertations in the field of judo. And the last place (one interconnection) corresponds to the decade, in which the analyzed Russian dissertations in the field of judo were carried out.

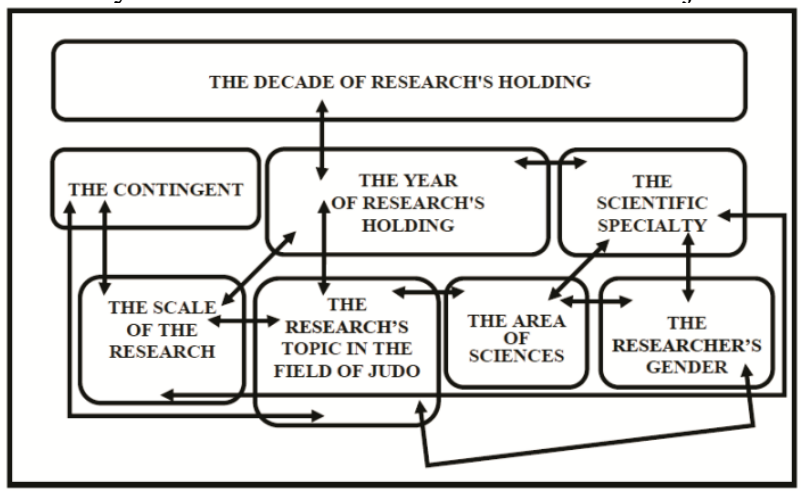

Fig. 10. Relationships between selected determinants of the analyzed Russian dissertations in the field of judo ( $\mathrm{p} \leq 0.05$; according to Pearson's criterion of agreement $\mathrm{X}^{2}$ with the normalization of its value in relation to the sample size according to Cramer's V test; $n=134$ ).

\section{The discussion of the results}

From our point of view, the effectiveness of the sports' preparation in judo can increase if the quality of the scientific and methodological support in terms of dissertational researches' conducting is improved within the following spectra of scientific knowledge:

- the first spectrum - the expansion of areas of the dissertational researches - their conduct in psychology, in biology and medicine in a larger number, as well as, in new areas - technical sciences, philosophy, culturology, sociology, chemistry, biomechanics and others;

- the second spectrum - expanding the number of researches within the framework of an incompletely investigated contingent - the preschoolers and the younger schoolchildren, the judokas of adolescence and the youth, the juniors, the students involved in the educational training groups and the groups of sports' improvement, the qualified athletes and the athletes of senior sports' categories, the military personnel, the coaches, the teachers, the female judokas and the judges;

- the third spectrum - the first direction of expanding the topics of the dissertational researches - their conduct on an incompletely researched topic - in the field of the longterm preparation, in the field of strength's preparation's organizing and strength's preparedness's increasing, in the field of endurance's and working capacity's increasing, in the field of coordination's abilities' formation, and such topics as complexes for the formation of physical abilities, planning, programming, modeling, forecasting, the organization as a management's function, the assessment's technologies, the sports' preparation, training in education, the individualization, the organization of sports' training and increasing sports' training, increasing competitive (sports') reliability, the range of judo's influence on health and athlete's body's condition, the organization of psychological 
training and improving psychological preparedness, the technologies of sports' selection, judo's teaching of the military personnel, using of judo's means in physical education, the mechanics of reducing the subjectivity of judo's refereeing, the technologies of education and development by means of judo;

- the third spectrum - the second direction of expanding the topics of the dissertational researches - their implementation in new areas - the analysis of methods for the development of judokas' speed abilities (for example, speed's increasing of performing a single complex coordination's motor action) and the flexibility (for example, the joint mobility), the mechanisms of mastering "verbal judo", the technologies of the application of "judo's strategy" by judokas, as well as, other topics.

\section{Conclusion}

Therefore, it can be concluded that the number of the doctoral dissertations in the field of judo is negligible, and also that the female researchers are very insignificantly involved in researches on this issue. The latter leads the situation to the fact that male researchers write about how to manage training in female judo, which is debatable in terms of expediency. In particular, a decrease in the number of completed researches in the field of judo in the period from 2010 to the present was revealed compared to the period of the two thousandth years, which is a negative trend. There is a narrow range of the dissertations in the field of judo through the prism of various fields of science: for example, the overwhelming majority of works are the pedagogical researches, while the complex scientific and methodological support should cover the entire spectrum of areas of scientific knowledge. At the same time, it should be noted that within the framework of the dissertational researches in the field of judo, a wide range of contingent is covered, however, the number of works is minimal for a number of positions of this spectrum. The topics of the dissertational researches in the field of judo correlate with a fairly large number of sections, however, the number of works is sufficient only in some of them.

\section{References}

1. J. Thompson, J. Jenkins, Verbal Judo. The Martial Art of Mind and Speech, St. Petersburg, Peter, 256 pages (2016). Series "To himself a psychologist"

2. D. Joffe, M. Quack, Judo's Strategy. How to make the strength of competitors an advantage, St. Petersburg, Prime EUROSNAK, 176 pages (2005). Project "Harvard Business School"

3. Bushido. Samurai military canon with comments, Moscow, AST Publishing House, 336 pages (2016). Illustrated military history

4. A. Wats, The Zen Path : Sources, Principles, Practice, Moscow, Sofia, 288 pages (2015)

5. Ya. K. Koblev, System of long-term training of international-class athletes in the struggle of judo, abstract of the dissertation ... of a doctor of pedagogical sciences, 13.00.04, State Central Institute of Physical Culture, Moscow, 38 pages (1990)

6. O. A. Sirotin, Psychological and pedagogical basis for the individualization of sports' training of judokas, abstract of the dissertation ... of a doctor of pedagogical sciences, 13.00.04, Ural State Academy of Physical Culture, Moscow, 49 pages (1996)

7. A. V. Eganov, Management of the training process to improve the sports' skills of judokas, abstract of the dissertation ... of a doctor of pedagogical sciences, 13.00.04, Ural State Academy of Physical Culture, Chelyabinsk, 41 pages (1999) 
8. V. G. Pashintsev, The planning technology of long-term training of judokas, abstract of the dissertation ... of a doctor of pedagogical sciences, 13.00.04, Moscow City Pedagogical University, Moscow, 52 pages (2001)

9. V. V. Izvekov, The system for managing of female training in wrestling: judo's example, dissertation abstract ... of a doctor of pedagogical sciences, 13.00.04, AllRussian Research's Institute of Physical Culture and Sports, Moscow, 46 pages (2001)

10. A. G. Levitsky, Management of the process of training judokas taking into account the level of individual readiness for competitive activity, abstract of the dissertation ... of a doctor of pedagogical sciences, 13.00.04, St. Petersburg State Academy of Physical Culture named after P. F. Lesgaft, St. Petersburg, 50 pages (2003)

11. V. G. Pashintsev, Adaptation of bioenergy processes in the development of endurance and speed-power qualities of qualified judokas, abstract of the dissertation ... of a doctor of biological sciences, 03.03.01, Moscow State Academy of Veterinary Medicine and Biotechnology named after K. I. Skryabin, Moscow, 42 pages (2015)

12. S. B. Elipkhanov, Management of long-term strength training in female judo, abstract of the dissertation ... of a doctor of pedagogical sciences, 13.00.04, Adygea State University, Maykop, 50 pages (2015)

13. M. V. Gabov, R. Z. Valeev, Yu. G. Martemyanov, Effectivization of competitive performance of skilled judokas with hearing impairments, Theory and Practice of Physical Culture, 5, 23 (2015). URL : http://www.teoriya.ru/ru/node/3791

14. I. D. Svishchev, V. A. Chuvilin, Structure of competitive match depending on display of motor activity dominant of judokas, Theory and Practice of Physical Culture, 7, 25 (2015). URL : http://www.teoriya.ru/ru/node/3864

15. V. A. Adolf, L. K. Sidorov, M. D. Kudryavtsev, A. Y. Osipov, A. Y. Bliznevsky, Precompetitive fitness methods applied by Russian judo's teams prior to international events, Theory and Practice of Physical Culture, 9, 22 (2018). URL : http://www.teoriya.ru/ru/node/9431

16. O. Koptev, Competitive competence structure in judo, Human. Sport. Medicine, 18(2), 35-44 (2018). DOI : https://doi.org/10.14529/hsm180204. (In Russian)

17. G. A. Kuzmenko, E. A. Kabanova, T. N. Lugovskikh, Psychomotor and speed qualities and mindsets cultivation of junior judokas for competitive progress, Theory and Practice of Physical Culture, 8, 5 (2018). URL : http://www.teoriya.ru/ru/node/8967

18. A. G. Levitsky, V. A. Kuvanov, V. A. Dorofeev, National judo's team qualification for 2020 Olympics in Tokyo: strategies, options and prospects, Theory and Practice of Physical Culture, 4, 29 (2019). URL : http://www.teoriya.ru/ru/node/10727

19. A. G. Levitsky, D. A. Matveyev, A. A. Potsipun, A. V. Shabaev, Advanced foot sweep (de ashi harai) throw technique in judo: body position analysis, Theory and Practice of Physical Culture, 7, 23 (2016). URL : http://www.teoriya.ru/ru/node/5005

20. A. G. Levitsky, D. A. Matveyev, A. A. Potsipun, E. Y. Gaponova, Body position control in o-soto-gari throws performed in competitive bouts, Theory and Practice of Physical Culture, 5, 24 (2017). URL : http://www.teoriya.ru/ru/node/6739

21. A. G. Levitsky, D. A. Matveyev, A. A. Potsipun, O. V. Oshina, O. V. Kholodkova, Biomechanical classification of actions in wrestling, Theory and Practice of Physical Culture, 10, 23 (2017). URL : http://www.teoriya.ru/ru/node/7698

22. A. G. Levitsky, D. A. Matveyev, A. A. Potsipun, O. V. Nerobeeva, Hip throw biomechanics analysis for wrestling sports, Theory and Practice of Physical Culture, 8 , 28 (2018). URL : http://www.teoriya.ru/ru/node/9244 
23. D. A. Matveev, A. A. Potsipun, O. V. Oshina, A. G. Levitsky, Throw technique biomechanics in competitive wrestling, Theory and Practice of Physical Culture, 6, 30 (2018). URL : http://www.teoriya.ru/ru/node/8592

24. A. G. Levitsky, D. A. Matveyev, A. A. Potsipun, O. V. Oshina, Body mass center travel trajectory analysis for ko-uchi-gari in judo bouts, Theory and Practice of Physical Culture, 5, 22 (2019). URL : http://www.teoriya.ru/ru/node/10755

25. O. V. Borisenko, S. I. Loginov, L. I. Lubysheva, The influence of training experience on morphofunctional indices and physical fitness of male judokas aged 8-10, Theory and Practice of Physical Culture, 12, 19 (2013). URL : http://www.teoriya.ru/ru/node/1716

26. A. F. Zekrin, F. Kh. Zekrin, V. V. Zebzeev, Anthropometric characteristics of junior judokas of different weight groups, Theory and Practice of Physical Culture, 4, 4 (2015). URL : http://www.teoriya.ru/ru/node/3568

27. M. Tkachuk, A. Levitskii, A. Sobolev, Morphogenetic markers of fast trainability in wrestling, Human. Sport. Medicine, 19(1), 130-134 (2019). DOI : https://doi.org/10.14529/hsm190118. (In Russian)

28. A. V. Litmanovich, A. A. Martin, V. I. Razumov, Logical scheme based fight control strategies in martial arts: judo's case study, Theory and Practice of Physical Culture, 11, 7 (2018). URL : http://www.teoriya.ru/ru/node/9688

29. E. A. Kabanova, G. A. Kuzmenko, Ch. T. Ivankov, Excelling training of junior heavy weight's judokas for high-speed confrontation strategy, Theory and Practice of Physical Culture, 2, 63-65 (2020). URL : http://www.teoriya.ru/ru/node/11309. (In Russian)

30. A. G. Levitsky, G. V. Rudenko, D. A. Simakov, Tactical problem solving algorithms for judokas of various skill levels, Theory and Practice of Physical Culture, 4, 80-82 (2020). URL : http://www.teoriya.ru/ru/node/11498. (In Russian)

31. R. B. Elipkhanov, Long-term strength training of female judokas, Theory and Practice of Physical Culture, 8, 78-84 (2013). URL : http://www.teoriya.ru/ru/node/728. (In Russian)

32. B. Wieslaw, O. Zbigniew, The peculiarities of coaching of young female judokas and their effect on athletic performance, Theory and Practice of Physical Culture, 10, 20 (2014). URL : http://www.teoriya.ru/ru/node/2596

33. V. G. Pashintsev, Glycolytic loading in training of judokas, Theory and Practice of Physical Culture, 9, 11 (2013). URL : http://www.teoriya.ru/ru/node/1567

34. A. A. Pseunok, M. A. Mugotlev, M. N. Silantyev, Heart rate and salivary electrolyte concentration of 10-12 year-old judokas, Theory and Practice of Physical Culture, 12, 17 (2018). URL : http://www.teoriya.ru/ru/node/9783

35. S. A. Pelipenko, Development of aerobic-anaerobic working capacity of judokas by means of interval run, Theory and Practice of Physical Culture, 7, 80-84 (2013). URL : http://www.teoriya.ru/ru/node/684. (In Russian)

36. V. G. Pashintsev, A. M. Surkov, Development of speed-strength glycolytic endurance in judo, Theory and Practice of Physical Culture, 3, 6 (2015). URL : http://www.teoriya.ru/ru/node/3504

37. S. K. Bagadirova, F. S. Brantova, E. A. Potokova, F. P. Khakunova, Goal-setting in psychological structure of sports' activity as a factor of increase of efficiency of judo's training process, Theory and Practice of Physical Culture, 8, 17 (2015). URL : http://www.teoriya.ru/ru/node/3965 
38. S. K. Bagadirova, Psychological aspects of design and implementation of training model in judo, Theory and Practice of Physical Culture, 6, 16 (2020). URL : http://www.teoriya.ru/en/node/11894

39. Ya. I. Yakovlev, I. I. Druziyanov, N. D. Kronnikov, S. V. Semenov, National fundamental sports for olympic accomplishments of yakut athletes, Theory and Practice of Physical Culture, 7, 35 (2018). URL : http://www.teoriya.ru/ru/node/8871

40. L. V. Pertseva, M. S. Ponomareva, A. V. Belyaeva, Benefits of Sakha ethnic sports for physical progress of beginner judo's trainings, Theory and Practice of Physical Culture, 10, 26 (2019). URL : http://www.teoriya.ru/ru/node/11664

41. M. P. Danilova, V. G. Torgovkin, Modeling of technical-tactical skills of studentsjudokas in university conditions, Theory and Practice of Physical Culture, 2, 78-80 (2013). URL : http://www.teoriya.ru/ru/node/339. (In Russian)

42. V. V. Zebzeev, O. S. Zdanovich, Analysis of special fitness of junior judokas, Theory and Practice of Physical Culture, 2, 68-70 (2013). URL : http://www.teoriya.ru/ru/node/334. (In Russian)

43. O. O. Gagarina, Technology of teaching junior judokas flying rolls based on the use of orientation basis of actions and allocation of main reference points, Physical culture: upbringing, education, training, 6, 39-41 (2014). URL : http://www.teoriya.ru/ru/node/3176. (In Russian)

44. D. A. Mikhaylova, A. G. Levitsky, G. V. Rudenko, Ways of Acculturation to Physical Culture Depending on Level of Organization of Physical Activity in Free Time, Theory and Practice of Physical Culture, 11, 14 (2014). URL : http://www.teoriya.ru/ru/node/2608

45. K. V. Yugay, Strength abilities providing hold efficiency of judokas of different categories, Theory and Practice of Physical Culture, 5, 21 (2014). URL : http://www.teoriya.ru/ru/node/2164

46. O. V. Borisenko, S. I. Loginov, L. I. Lubysheva, Development of coordination abilities of primary school age children using judo in context of modular technology, Theory and Practice of Physical Culture, 6, 24 (2015). URL : http://www.teoriya.ru/ru/node/3828

47. S. I. Loginov, A. A. Egorov, V. A. Ermakov, Data mining system: “Judo's sport's school" module, Theory and Practice of Physical Culture, 2, 29 (2015). URL : http://www.teoriya.ru/ru/node/3005

48. A. V. Volkov, I. A. Panchenko, A. P. Babchenko, Training load volume and goal as key factors of performance control in judo, Theory and Practice of Physical Culture, 7, 24 (2017). URL : http://www.teoriya.ru/ru/node/6666

49. A. A. Baryaev, Physical fitness tests in blind sports, Theory and Practice of Physical Culture, 11, 12 (2018). URL : http://www.teoriya.ru/ru/node/9692

50. T. K. Kim, A. A. Podlesnykh, Rating benefits of musculoskeletal system disorders prevention and correction method based on motor profiles in judo, Theory and Practice of Physical Culture, 1, 32 (2018). URL : http://www.teoriya.ru/ru/node/7937

51. A. B. Petrov, S. P. Bodko, V. K. Seisebayev, D. A. Pokhachevsky, Training process efficiency criteria in professional sambo's and judo's sports, Theory and Practice of Physical Culture, 8, 98 (2019). URL : http://www.teoriya.ru/ru/node/10823

52. E. R. Yakhontov, Methodology of sports' and pedagogical researches, a course of lectures, St. Petersburg State Academy of Physical Culture named after P. F. Lesgaft, St. Petersburg, [without publisher], 42-50 (2002). (In Russian). 